\title{
Comprehending a Non-text: A Study of Gender-based Differences in EFL Reading Comprehension
}

\author{
Alireza Ahmadi \\ Shiraz University, Iran \\ Email: arahmadi@shirazu.ac.ir \\ Shaban Mansoordehghan \\ Islamic Azad University of Hashtgerd, Iran
}

\begin{abstract}
The present study investigated the gender-based differences in EFL reading comprehension in the Iranian EFL context. To illuminate the possible effect of background knowledge, the study focused on a non-text. The non-text was followed by 10 reading comprehension questions. Eight questions focused on the antecedent-reference relationship; one question asked for the topic of the text and one for the main idea. A total of 53 intermediate university students took part in the study. They were indicated to be at the intermediate level of reading proficiency after taking a reading comprehension test. The results indicated that males were more successful in constructing the meaning for the non-text in general and in performing on the three types of items in particular. In other words, they were more successful in dealing with a context of ambiguity. It was concluded that readers compensate for the lack of meaning in a text by making themselves activate a possibly related schemata and as such even meaningless texts will carry meaning.
\end{abstract}

Index Terms - non-text, gender-based differences, schema, reading comprehension

\section{INTRODUCTION}

Recent models of text comprehension agree on the idea that reading comprehension embraces three components: text, mental representation (world knowledge), and integrated situation model (Prestin, 2008). The reader decodes the words to get a mental representation of the text, but this gives him a superficial understanding of the text. The reader has to integrate the text-based knowledge and world knowledge to get a deeper understanding. This integration is accomplished through building a situation model (e.g. Perfetti, Landi, and Oakhill, 2005). What all these models of reading comprehension suggest is that reading comprehension is an interactive process of making meaning and requires effort on the part of readers (Anderson, 1999; Grabe, \& Stoller, 2002; Erten and Raz1, 2009). The reader integrates different sources of knowledge to construct a cognitive representation of the text information (Alptekin, 2006; Donin et al., 2004; Ehrlich, 1990; Fukkink et al., 2005; Kintsch, 1998; McNamara, 2001; McNamara \& Kintsch, 1996; Salmero'n, Kintsch, \& Can as, 2006; Van den Broek, Rapp, \& Kendeou, 2005; Wei, 2009). However, this cognitive representation may not be realized completely since different factors may distort the comprehension. A number of such factors have been studied in terms of their effect on reading comprehension.

For example, reading comprehension has been studied in terms of its relation to readers' attitude (McKenna, Kear \& Ellsworth, 1995; Smith and Wilhelm, 2002), reading strategies (Anderson, 1991; Barnett, 1988; Brantmeier, 2002; Palincsar \& Brown, 1984; Pearson \& Fielding, 1991; Pressley, 2000; Pressley, Wharton-McDonald, Mistretta-Hampston, \& Echevarria, 1998; Sarig, 1987; Singhal, 2001;), EFL proficiency (Alderson, 2000; Keshavarz, Atai, and Ahmadi, 2007), and cultural familiarity (Alptekin, 2006; Erten, and Razi, 2009; Johnson, 1981). Among these, the effect of background knowledge (schema) on reading comprehension has received special attention, and a good number of studies have been conducted in this regard. All these studies underline the key role that background knowledge plays in reading comprehension (Afflerbach, 1990a, 1990b; Anderson and Pearson, 1984; Armand, 2001; Bernhardt, 1991; Brantmeier, 2003 \& 2004; Carrell, 1987; Carrell, Devine, \& Eskey, 1988; Fincher-Kiefer, 1992; Fincher-Kiefer, Post, Greene and Voss, 1988; Grabe, 1991; Grabe \& Stoller, 2002; Keshavarz, Atai, and Ahmadi, 2007; Koda, 2005, \& 2007; Nassaji, 2002; Pressley, 2000; Rumelhart, 1980; Swaffar, Arens, \& Byrnes, 1991; Van Oostendorp,1991; Voss, Vesonder \& Spilich, 1980). It has been mentioned that no other factor influences understanding more than prior knowledge (Alexander and Jetton, 2000). "Prior knowledge, also termed world knowledge or background knowledge, is generally defined as the sum of what a person knows about the content of a text" (Brandao, \& Oakhill, 2005, pp. 1-2). It includes whatever readers already know about events, ideas or objects described to them, and influences the meaning that they construct from the text. The importance of the prior knowledge is represented in schema theory of reading (Anderson and Pearson, 1984), which holds that "comprehension occurs when the reader builds up systems of relationships between existing schemas and the information presented in the text" (Kozminsky and 
Kozminsky, 2001, p.2).

Prior knowledge is closely related to text coherence (Kintsch, 1994). To construct integrated and coherent text representation, readers should anchor onto their prior knowledge to fill the gaps in the text. "In other words, they need to build links between the text and their prior knowledge to fill in information that is left implicit" (Brandao, \& Oakhill, 2005; p.2).

It has also been found that the limited capacity of the working memory may be overloaded by the extra efforts that readers make when reading. Micro-level linguistic features may place so much demand on the readers that not enough resources can be allocated to macro-level textual analysis (Afflerbach, 1990b; Alptekin, 2006). However, the cognitive load can be reduced by activation of the background knowledge (Carrell, 1988; Ellis, 2001; Nassaji, 2002; Pulido, 2004) and hence readers can allocate more attentional space for textual analysis and interpretation of more unfamiliar and newer elements in the text.

An important implication of all these studies is that probably the first factor to explain individual differences in reading comprehension is background knowledge. However, background knowledge is not the only factor that may explain the individual differences in reading comprehension. There are other factors responsible for such differences especially when background knowledge is more or less the same across individuals. One of such factors which has been focused on to explain the extent of success or failure in reading comprehension is gender. The issue of gender-based differences in reading comprehension is depicted in a number of studies. These studies have reached different conclusions, most favoring females, some favoring males and several others indicating no significant difference between genders (Brantmeier, 2001, 2003; Bügel and Buunk, 1996; Carlton and Harris (1992); Cole (1997); Hyde and Linn, 1988; Myers, 2002; Pae, 2004; Rosén, 2001; Yongqi, 2002).

Different explanations have also been put forward for gender differences in reading comprehension. Connell and Gunzelmann (2004) consider the relationship between gender and reading as a complex problem which is influenced by many factors including social, cultural, biological, etc. Brain-based gender differences suggest that boys and girls use different parts of their brain, with each group exhibiting both stronger left-hemisphere and right-hemisphere capacities. The left hemisphere strength of girls favors them in speaking, reading and writing in the early grades whereas the left-hemisphere strength of boys favors them in categorizing and recalling factual information. Girls get the benefit of their right-hemisphere strength in being more empathetic and more understanding and reflective of others' feelings than boys, while boys use their right-hemisphere strength to outperform girls in subjects such as science, math and geography (Connell and Gunzelmann, 2004).

Smith and Wilhelm (2002) explain gender differences based on attitude whereas Brantmeier (2001 \&2003) claims that gender and passage content are key variables that are associated with individual differences in L2 reading comprehension.

Similarly, Bügel and Buunk (1996) had formerly found that the topic of text is an important factor explaining gender-based differences in the reading part of the national foreign language examination. Males outperformed females on MC comprehension items for essays about laser thermometers, volcanoes, cars, and football players. Females outperformed males on the comprehension tests for essays on topics such as midwives, a sad story, and a housewife's dilemma.

Pae (2004) found that passage content was not a reliable factor to explain the interaction between gender and performance in reading comprehension, and that item type might provide a better index in this regard. Studying the Korean students taking the Korean National Entrance Exam, Pae found that items classified as Mood/Impression/Tone tended to be easier for females, whereas items classified as Logical Inference were more likely to favor males regardless of item content.

In a review article, Al-Shumaimeri (2005) claimed that most of reading comprehension studies use gender-oriented reading texts and that there was a need for more research on L2/FL reading comprehension using gender-neutral text,; although, some studies like Bügel and Buunk (1996) had formerly indicated a gender-based difference even with neutral texts. They included a gender-neutral text in their study and found that males performed significantly better than females.

Finally, some other studies have related gender differences in reading comprehension to different strategies that readers employ (Abu-Rabia, 2004; Bacon, 1992; Chavez, 2001; Kaylani, 1996; Oxford et al, 1996; Oxford et al, 1993; Sheorey, 1999;).

The review of gender studies indicates controversial findings about gender differences. It also pinpoints the need for more studies to be conducted on gender-neutral text to provide us with a better picture as to the gender differences in reading comprehension. This is because text familiarity has an influential effect on comprehension and may distort the picture presented about gender differences. The present study is an attempt in this regard to fill the gap in gender studies on neutral texts. However, the present study is basically different from the other studies in the sense that a non-text has been used in the study to control for the effect of background knowledge. That is, contrary to other reading comprehension studies, the present study has focused on a non-text created by the researcher to see how different genders react to it.

The study may provide the literature with valuable information concerning the issue of gender differences in reading comprehension since it is carried out in an Iranian EFL context which embraces few studies in this regard. It can 
provide information as to whether the gender differences in reading comprehension are transferable across borders. This is what is claimed by Rosen (2001) who found in his study that gender differences existed across different countries with almost consistent pattern of female advantage.

\section{Research Questions}

This study aimed at investigating the role of gender in EFL reading comprehension. However, as mentioned before, the study utilized a non-text to examine gender differences. The following questions were hence put forward:

1. What is the effect of gender on the students' performance on items focusing on antecedent-reference relationship in a non-text?

2. What is the effect of gender on assigning a topic to a non-text?

3. What is the effect of gender on finding the main idea of a non-text?

\section{METHOD}

\section{A. Participants}

A total of 53 intermediate university students took part in this study. The majority of the students were female (40 females and 13 males). This is the usual norm in the Iranian universities. Today, most of the Iranian university students in different fields of study are females. Similarly, about $70 \%$ of the students majoring in the English Language (TEFL, English Literature, English Translation, and Linguistics) are females. Therefore a balance of males and females, though desirable for statistical analysis, was not possible in the present study as two intact EFL classes (71 students) were selected based on convenience sampling. At first, they took a reading comprehension test based on which 53 were selected as the final sample.

\section{B. Instruments}

\section{The English Non-text}

A fabricated English non-text was the basic data collection instrument used in the present study (Appendix A). It consisted of 10 separate sentences taken from different texts. These sentences were put together in a way to create a seemingly coherent and cohesive text. Attempt was made to choose the sentences that seemed to make a unified text when put together. That is, it was tried to create a text that was not obviously nonsense; otherwise the participants could guess the research purpose and wouldn't provide any answers and therefore the whole text would be useless. Most of these sentences included a pronoun such as a demonstrative pronoun. Overall, a text of 133 words was made in which 8 pronouns or words were underlined in order for the students to find their appropriate references. Students were also expected to find an appropriate topic for the text, a general concept around which the paragraph revolved, and also to find the main idea of the text. Therefore, overall this non-text was followed by 10 reading comprehension questions, one question asked for the main idea of the text, one asked for the general topic or subject of the text, and 8 others asked for the reference of a particular word or pronoun. All the texts from which sentences were taken came from the textbook "Mosaic II" (by Werner, \& Nelson, 2007) which is written for intermediate students. All the sentences were taken from texts that seemed neutral to both genders. This was to reduce any possible effect of the background knowledge although the final product was a non-text.

The reason why such a non-text was created instead of using a real text was to reduce the possible effect of content familiarity or background knowledge.

The non-text was not examined for its difficulty level because first of all it was not a real coherent text and therefore using readability formulae didn't make much sense, and second because the study just aimed at finding the differences in reading comprehension based on gender.

Interview

About $20 \%$ of the participants (five males and five females) were randomly selected and interviewed after the test to see how they viewed the non-text. They were randomly selected from among the 53 participants who sat for the reading comprehension test.

\section{Data Collection Procedure}

The data of this study came from the participants' answers to ten reading comprehension questions of the fabricated text. It took students about 20 minutes to read the text and answer the questions. They were not aware of the purpose of research nor did they know anything about the fact that the text was not a real text or else their reaction to the questions would be different. Complementary data also came from those students interviewed after the test.

\section{Data Analysis}

The data collected underwent careful analysis. At first the papers were divided into two groups based on gender, and then the answers were carefully analyzed to find any patterns in the answers. All the answers were studied in three categories of the topic (subject), main idea, and antecedent-reference relationship and the frequency of each answer type was calculated and compared to the others. 


\section{RESUlts}

The results of the study are depicted in Tables 1-3 for reference, topic and main idea respectively. Table 1. depicts the results for the antecedent-reference category. There were eight items in this category. Since all the items were of the same type, the answers to the items were added and summarized as in Table 1. As indicated, males have resorted to exophoric references for only 5.77\% of the time. Almost the same is true for females who have used exophoric references $4.69 \%$ of the time. In contrast, endophoric reference has been used much more by the participants $(92.30 \%$ by males and $89.06 \%$ by females). That is to say, regardless of their gender, participants have preferred assigning endophoric references to exophoric references. Since the text was mostly incomprehensible and the words had no real references in the text; it's interesting to see that the participants have made themselves find a reference within the text rather than outside the text.

TABLE 1. DESCRIPTIVE STATISTICS FOR THE ANTECEDENT-REFERENCE QUESTIONS

\begin{tabular}{lll}
\hline & Male & Female \\
\cline { 2 - 3 } Endophoric & $92.3 \%$ & $89.06 \%$ \\
Anaphoric & $84.60 \%$ & $83.75 \%$ \\
Cataphoric & $7.70 \%$ & $5.31 \%$ \\
Exophoric & $5.77 \%$ & $4.69 \%$ \\
No answer & $1.92 \%$ & $6.25 \%$ \\
\hline
\end{tabular}

The Table also indicates that, within the endophoric references participants have preferred anaphoric references to cataphoric references.

The last point concerning the reference system as indicated in Table 1 is the row named "no answer". This row indicates the proportion of times that participants were not able to assign any reference to the target term. It is interesting that males were successful for $98.08 \%$ of the time. They failed to assign a reference less than $2 \%$ of the time. Females, however, were less successful in this regard. The Table indicates that they failed more than $6 \%$ of the time. Table 1 indicates that males have slightly excelled females in the use of all types of references and overall they have been more successful in trying to make references for the specified terms.

Table 2 below indicates the results of the study concerning the difference between males and females in applying a topic to the non-text. The participants were told to select a general concept that they thought was the focus of the text or that could stand as the title of the text. It is interesting to note that overall $25 \%$ of the female participants could not select a topic for the text. All the males, however, assigned a topic to the text. So the difference that was found between males and females in the previous section concerning assigning appropriate references to the specified words was also noticed in finding a topic. But the difference found in this section is much more noticeable.

TABLE 2.

DESCRIPTIVE STATISTICS FOR THE TOPIC SELECTION

\begin{tabular}{lll}
\hline & Male & Female \\
\cline { 2 - 3 } Taken from the $1^{\text {st }}$ sentence & $30.80 \%$ & $32.50 \%$ \\
Taken from the Last sentence & $7.70 \%$ & $10.00 \%$ \\
Taken from the $1^{\text {st }}$ and last sentence combined & $7.70 \%$ & $00.00 \%$ \\
Others & $53.80 \%$ & $32.50 \%$ \\
No answer & $00.00 \%$ & $25.00 \%$
\end{tabular}

The Table also indicates that about $30.80 \%$ of the males selected the topic from the first sentence of the text. Females, however, have been slightly more dependent on the first sentence as providing them with a topic for the whole text $(32.50 \%)$. The last sentence of the text was also used as a source of information. Ten percent of females and $7.7 \%$ of males relied on this sentence to find a topic for the text. Also 7.7\% of the males used a combination of the first and the last sentence as a source for the text topic. Examples of such topics were "society and change" or "children and change" in which the participant had selected a key term from the first sentence and a key term from the last sentence and had presented the combination of them as the text topic. None of the females, however, applied such a procedure. Overall, Table 2 indicates that $42.5 \%$ of females have selected the topic from either the first or the last sentence of the text, and only $32.5 \%$ preferred other parts of the text as a source for the topic. Males have treated a bit different in this regard. It can be seen in Table 2 that, although more or less the same finding is true for males in selecting the first or the last sentence as the source of topic, most of the males $(53.8 \%)$ have resorted to other parts of the text to find an appropriate topic for the text. Probably, that's why all the males were able to find a topic whereas $25 \%$ of females failed in this regard. This is also confirmed by comparing the last two rows of Table 2.

Table 3 depicts the differences between males and females in terms of selection of a main idea for the non-text. Similar to what they did in finding a topic, $12.5 \%$ of females were not able to find a main idea for the text whereas all the males were able to do so. Many females (42.5\%) selected the first sentence or a reformulation of it as the main idea and only $7.7 \%$ considered the last sentence as the main idea. In contrast, males preferred the last sentence over the first sentence. Table 3 indicates that $15.40 \%$ have expressed the first sentence as the main idea whereas $23.10 \%$ of males have preferred the last sentence. More or less the same percent of males and females have combined the first and the last sentence to make the main idea of the text. However, by and large, more females have used the first, the last or a 
combination of both as the main idea than males (57.5\% vs $46.2 \%)$. In return more males, almost twice the number of females, have referred to other parts of the text or have used their information of the whole text to write an appropriate main idea for the text. The difference between males and females is quite outstanding in this regard, $(53.80 \%$ vs $30.00 \%$ ). This finding is in line with the results found in the previous section about topic selection.

TABLE 3.

\begin{tabular}{lll} 
DESCRIPTIVE STATISTICS FOR THE MAIN IDEA SELECTION \\
\hline
\end{tabular}

\section{DISCUSSION}

The present study investigated gender-based differences in EFL reading comprehension. To illuminate the effect of background knowledge, the study focused on a non-text. The non-text was formed through putting together of ten irrelevant sentences, but each sentence was meaningful when considered in isolation. This may mean that the text had some ideas to transfer to students at sentential level but overall as a text it very probably lacked coherence and unity. As a whole, males were found to be more successful in assigning meaning to the incoherent non-text and therefore had a higher comprehension of it. That is, the majority of male students were able to answer most of the reading comprehension questions which were in completion format, whereas females were stuck in some questions and had a lower performance on the test.

In particular, the study indicated that all the males and most of the females were able to find the main idea behind the text and also a topic for the text. As participants were dealing with a non-text, their background text knowledge could be assumed to be zero or very negligible, but the fact that most of the students were able to assign a topic to the non-text or find the main idea behind it means that they have considered the non-text as a coherent text and in turn this means that probably they have activated a particular schema in their mind in assigning meaning to the whole non-text and creating a text instead. "If new information is incomplete, the reader makes inferences on the basis of the selected schema in order to fill in the missing parts" (Al-Shumaimeri, 2005). Evidence from those interviewed confirms this conclusion since most of them stated that the text was strange or complicated to grasp, however, none said it was non-sense (non-text). This is very interesting and could provide evidence for the powerful and of course complicated human ability in comprehending a text. It can be said that no matter how difficult the text is, since no text is more difficult to understand than a non-text, people can make sense of it. This can be justified as meaning does not reside just in the text rather it is constructed by the active participation of the readers in integrating different sources of knowledge. In other words, even if the text is meaningless, human beings try their best to find some meaning in it and activate a related schema. That's why the majority of participants in this study were successful in constructing meaning for the non-text. Of course this calls for more qualitative research in studying the mental process of comprehending a text on the part of males and females.

It is also interesting to note that the first sentence had a key role in activating the students' schema since many had tried to relate the main idea and topic of the text to the first sentence. This may indicate the effect of instruction. The students who took part in this study were basically familiar with the writing structure of English and had passed such courses as "paragraph writing", "advanced writing", and "English grammar". Therefore, they were expected to be familiar with issues like a topic sentence in a paragraph, the concluding sentence, etc. The fact that the appearance of the topic sentence or main idea in the first sentence is more common led many students to select the main idea and the topic of the text from this sentence. Similarly, since the last sentence usually provides the conclusion of a text, this sentence was also considered as a possible good source for the main idea and topic of the text.

The study also indicated that more males felt relaxed in using other parts of the text and not just the first or the last sentence as the possible sources for the main idea and topic (about 53\% vs about 32\%). Probably that's why all the males were able to assign a topic to the text or find a main idea whereas $25 \%$ and $12.5 \%$ of females could not do so respectively. This may mean that males are more flexible in their attempt to find a topic for the text. About eight percent of the males presented a combination of the terms in the first and the last sentence as the topic. In contrast females seem to look for pre-specified organization or framework in the text (that e.g. the first or the last sentence of a text usually provides more important information and are the most probable candidates for the topic). This is made clear when we notice that none of the females in this study used a combination of the first and the last line to form the topic. This point could also be confirmed by the results obtained from the items focusing on the antecedent-reference relationship (Table 1). More males anchored on non-common references, namely, exophoric and cataphoric references.

Another point about the present study is that since the non-text was not related to a specific topic, the idea that probably the text content had been more male oriented and therefore had helped males to perform better is not warranted. Of course, some previous studies had indicated that in neutral texts males were better performers in reading comprehension (Bugel and Buunk, 1996). So, one may speculate that a non-text is similar to a neutral text in the sense 
that males indicate better performance on non-texts. However, the idea of neutral text is an under-studied area and needs more research before sound conclusions can be made in this regard (Al-Shumaimeri, 2005; Bugel and Buunk, 1996).

The present study also indicated that in general both males and males had a successful performance on referential questions asking for the reference of specific words or pronouns in the text, though again males out-performed females in this area. Most of the participants tended to choose anaphoric references over exophoric references. This is interesting since in spite of the fact that in many cases the references assigned were not in line with the given words in terms of number or gender, and that they had no real references in the text. $19.23 \%$ of the references assigned by males and $20 \%$ of the references assigned by females were not in agreement with the specified pronouns in terms of number or gender. The participants had preferred to use endophoric references than to rely on or create exaphroic references. Within the endophoric references, males and females indicated the same pattern of choosing anaphoric references over cataphoric references. This is probably due to the fact that the anaphoric reference is more common than the cataphoric reference and in turn endophoric reference is more common than exophoric reference in daily language and especially in written discourse. Therefore students had selected the more common (salient) features in assigning reference to a given word. Many explanations have been put forward in the literature to account for the way we interpret pronoun-reference relationship. For example:

Parallelism: the entity in the same grammatical function in the previous clause is the antecedent. (Arnold 1995a; Caramazza and Gupta 1979; Sheldon 1974).

Subject as default antecedent: the most salient entity is the antecedent and grammatical subject is the most salient position. (Kuno 1976).

First mention as default antecedent: the most salient entity is the antecedent and the first entity in the utterance is the most salient (Gernsbacher \& Hargreaves 1988; Stevenson et al. 1994;).

Thematic roles: some thematic roles are more likely to be pronoun antecedents than others (Arnold 1995b; Stevenson et al. 1994).

It seems that the role of saliency is emphasized in some of these explanations. Also the most salient position for the antecedent of a given entity is in the same or preceding clause. This is exactly what found for many of the antecedents in the present study.

Several other explanations may be presented to account for the results of the present study. It can be said that males are more risk takers in performing on language tests. It has been suggested that girls are more reluctant to guess on multiple-choice questions than boys; boys overestimate their likelihood of success and hence take risks unknowingly, for which they are rewarded (Linn, et al. 1987. Similarly, males tend to guess more on multiple-choice exams whereas girls tend to omit the items they are not sure about (Bolger and Kellaghan, 1990). Of course the questions in the present test were in completion format, but it's possible that what Linn, et al. and Bolger and Kellaghan say about boy's risk taking is also true for completion type of items; that is, males do their best to write an answer even if they are not much sure about what they write whereas girls prefer to have a high level of certainty about the right answer. In other words, females tend to be more accurate and prefer everything to be orderly and organized. Lack of organization or framework as such may hinder them from presenting their real abilities. When interviewed for their answers, most of females stated that the text was confusing and that they could not find a good topic for the text, or the main idea behind it, so they preferred to leave it unanswered. Males also expressed the same idea that the text was very confusing. However, they said, they had done their best to find a topic and write their best guess or answer. Girls who had succeeded in finding a topic for the text (two out of five interviewed) also had a similar idea to the boys that they were not much sure but sticked to their best guess. So overall it seems that males are more successful in tolerating or making sense of a non-text.

Still another explanation for the results obtained in this study may come from the test form. In his study of Spanish students, Brantmeier (2003), found that males performed better on the passage about boxing than on the passage about the housewife when the dependent variable was written recall, but males performed worse on the boxing passage than on the housewife passage when the dependent variable was multiple choice question. Hence the effect of test form was indicated to be more important than the effect of content familiarity. Similarly, the fact that only completion items were used in the present study can, at least partly, explain the results. It's possible that a similar study with different test forms provides different results in this regard. Equity concerns would also demand for a mix of different types of assessment instruments (Mazzeo, Schmitt, and Bleistein, 1993)

In line with the test form, item type may also have an important role in interpreting the results of such studies. Anderson et al (1991) found that test items affect how readers interact with the text and hence the type of answers they provide. Alptekin (2006) also found that when items required inference on the part of readers their reliance on the text reduced and they tried to relate the textual content to their reasoning and pragmatic knowledge to have a meaningful mental representation of the text. Pae (2004) also found that items classified as Mood/Impression/Tone tended to be easier for females, whereas items classified as Logical Inference were more likely to favor males regardless of item content. The questions in the present study were of two kinds, some asking the readers to find the topic or the main idea of the text, and some others asking for the reference of some given words. Probably a similar study with other types of questions produces different results. 


\section{CONCLUSION}

This study focused on the issue of gender differences in EFL reading comprehension. The study utilized a non-text to see how different genders would react to it. The majority of the participants were successful in making sense of the text or in finding antecedents for the given words or pronouns. It was concluded that no text is completely non-sense and that human beings are able to pull all their linguistic and cognitive resources together to make sense of the most complicated or even meaningless and fabricated texts The results of all the sections especially those related to finding a topic and main idea were very closely related and lent support to the conclusion that males are more successful in dealing with context of ambiguity or in making sense of the non-texts. The study indicated that $25 \%$ and $12.5 \%$ of females were not able to find any appropriate topic or main idea for the text respectively, whereas all the males, with no exception, were able to find a topic or a main idea for the text. The only case in which males failed to come up with an answer was in assigning references to the specified pronouns or words and even in that case males were still out-performers.

\section{IMPLICATIONS}

The present study may help the literature on gender-based differences in reading comprehension by providing information about an under-studied context, Iranian EFL context, and by focusing on a different type of text, a non-text, which may give us new information about gender issues.

The results may also provide some hints, though mostly theoretical, for materials developers to consider and be aware of the gender differences in the selection of appropriate texts for reading comprehension.

Teachers may also benefit from the results. As stated by Brantmeier (2003, p. 10)

Course instructors... cannot change the gender or the background of the learners, but they can provide in-class activities that inform readers of new information they are required to process in the text. An instructor can explain and clarify cultural as well as linguistic meanings that are relevant to the reading experience. Although an instructor cannot teach all the possible instances in which gender-related differences in subject matter may affect comprehension, some of the appropriate cultural schemata that the student lacks can be effectively taught.

In general, one can say that at least teachers who are equipped with the knowledge of gender differences in reading comprehension are more likely to be successful in dealing with those differences when they appear in their reading comprehension classes. They could also be more realistic in assessing their students' reading ability.

The study may also help test constructors. Caution should be employed in using test content and item types which provide us with an assessment as fair as possible. This may mean that we need to rely on different test formats and item types to reduce the bias.

\section{LIMITATIONS OF THE STUDY}

The findings of the present study should be treated cautiously before one can make any generalizations. First of all, the study is limited due to the small sample used. Although, use was also made of interview to somehow compensate for the sample size; it is, by no means, enough. Further, the study suffers from the fact that only one text with 10 questions was selected to compare the gender differences. This was done because the text was a fabricated one; however, a similar study with more texts and questions would be more informative.

\section{APPENDIX}

Read the following text carefully and fill in the blanks with the appropriate answers. Write only one answer for each question. For question 1, specify a general concept about which the text is talking and for question 2 write the main idea of the text in a sentence.

Society teaches children to act like male or females at a young age. As a matter of fact they are essential. Something that we know for certain is that even the ancients were fascinated by ideas of this. For example, personality traits such as shyness seem to be inherited. The primitive, often brutal, struggle to reach the top is an irresistible challenge to the human need for adventure. This is true of some animals, and it is especially true of human beings. In the last several decades, however, researchers have been so active in this area that we understand more about the mind today than we ever imagined possible. Yet the reason for this gap has little to do with natural ability. Today, change is virtually unavoidable. Some of these changes are radical.

1. The topic of this paragraph is

2. The main idea of this text is

3. The word "they" in line 2 refers to

4. The word "this" in line 3 refers to

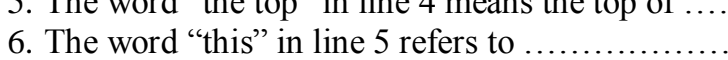

7. The word "it" in line 5 refers to ...

8. The word "this" in line 7 refers to 
9. The word "this gap" in line 8 means the gap between ........ and .......

10.The word change in line 8 means change of/to

\section{REFERENCES}

[1] Abu-Rabia, S. (2004). Teachers' role, learners' gender differences, and FL anxiety among seventh grade students studying English as a FL. Educational Psychology, 24(5), 711-721.

[2] Afflerbach, P. (1990a). The influence of prior knowledge and text genre on readers' prediction strategies. Journal of Reading Behavior, 22(2), 131-48.

[3] Afflerbach, P. (1990b). The influence of prior knowledge on expert readers' main ideas construction. Reading Research Quarterly, 25 (1), 31-46.

[4] Alderson, J. C. (2000). Assessing reading. Cambridge: Cambridge University Press.

[5] Alexander, P.A., \& T.L. Jetton. 2000. Learning from text: A multidimensional and developmental perspective. In M. L. Kamil, P. B. Mosenthal, P. D. Pearson, \& R. Barr, (Eds.), Handbook of reading research: Vol. 3, (pp.285-310). Mahwah, New Jersey: Lawrence Erlbaum.

[6] Alptekin, C. (2006). Cultural familiarity in inferential and literal comprehension in L2 reading. System, 34, 494-508.

[7] Al-Shumaimeri. Y. A. N (2005). Gender Differences in Reading Comprehension Performance in in relation to content familiarity of gender-neutral texts. Paper presented at the The second international conference: Language, culture and literature, Minia University, Eygept.

[8] Anderson, N. J. (1999). Exploring second language reading. Boston, MA: Heinle \& Heinle.

[9] Anderson, N. J., Bachman, L., Perkins, K., \& Cohen, A. (1991). An exploratory study into the construct validity of a reading comprehension test: Triangulation of data scores. Language Testing, 8, 41-66.

[10] Anderson, N. J. (1991). Individual differences in strategy use in second language reading and testing. The Modern Language Journal, 75(4), 460-472.

[11] Anderson, R. C., \& Pearson, P. D. (1984). A schema-theoretic view of reading comprehension. In P. D. Pearson (Ed.), Handbook of reading research (pp. 255-291). New York: Longman.

[12] Armand, F. (2001). Learning from expository texts: Effects of the interaction of prior knowledge and test structure on responses to different question types. European Journal of Psychology of Education, 16, 67-86.

[13] Arnold, J. (1995a). Reference, verbal form, and information structure in Mapudungun. Paper presented at the Meeting for the Society for the Study of Indigenous Languages of America, Albuquerque, NM.

[14] Arnold, J. (1995b). The roles of context and surface information in pronoun disambiguation. Qualifying Paper, Stanford University.

[15] Bacon, S. M. (1992). The relationship between gender, comprehension, processing strategies, and cognitive and affective response in foreign language listening. Modern Language Journal, 76, 161-178.

[16] Barnett, M.A. (1988). Reading through context: How real and perceived strategy use affects FL comprehension. The Modern Language Journal, 72, 150-162.

[17] Bernhardt, E. B. (1991). Reading development in a second-language. Norwood, NJ: Ablex.

[18] Bolger, N., \& Kellaghan, T. (1990). Method of measurement and gender differences in scholastic achievement. Journal of Educational Measurement, 27, 165-174.

[19] Brandao, A. C. P. \& Oakhill, J. (2005). How do you know this answer? Children's use of text data and general knowledge in story comprehension. Reading and Writing,18, 687-713. DOI 10.1007/s11145-005-5600-x

[20] Brantmeier, C. (2001). Second language reading research on passage content and gender: Challenges for the intermediate-level curriculum. Foreign Language Annals, 34(4), 325-333.

[21] Brantmeier, C. (2002). Second language reading strategy research at the secondary university levels: Variations, disparities, and generalizability. The Reading Matrix, 2(3), 1-14

[22] Brantmeier, C. (2003). Does gender make a difference? Passage content and comprehension in second language reading. Reading in a Foreign Language, 15 (1), 10-27.

[23] Brantmeier, C. (2004). Building a comprehensive theory of adult foreign language reading: A variety of variables and research methods. The Southern Journal of Linguistics, 27, 1-7.

[24] Bugel, K. \& Buunk, B. P. (1996). Sex differences in foreign language text comprehension: The role of interests and prior knowledge. The Modern Language Journal, 80, 15-31.

[25] Caramazza, A. \& Gupta, S. (1979). The roles of topicalization, parallel function and verb semantics in the interpretation of pronouns. Linguistics, 3, 497-518.

[26] Carrell, P. L. (1987). Content and formal schemata in ESL reading. TESOL Quarterly, 21, 461-481.

[27] Carrell, P. L. (1988). Some causes of text-boundedness and schema interference in ESL reading. In P. L. Carrell, J. Devine, \& D. Esky (Eds.), Interactive approaches to second language reading (pp. 101-113). Cambridge: Cambridge University Press.

[28] Carrell, P. L., Devine, J., \& Eskey, D. E. (1988). Interactive approaches to second language reading. Cambridge: Cambridge University Press.

[29] Carlton, S. T. \& Harris, A. M. (1992). Characteristics associated with differential item functioning on the scholastic aptitude test: gender and majority/minority group comparisons. ETS Research Report, 64-92.

[30] Chavez, M. (2001). Gender in the language classroom. New York: McGraw Hill.

[31] Cole, N. S. (1997). The ETS gender study: How males and females perform in educational settings. Princeton, NJ: Educational Testing Service.

[32] Connell, D., \& Gunzelmann, B. (2004, March). The next gender gap: why are so many boys floundering while so many girls are soaring? Instructor, March, 14-17.

[33] Donin, J. Graves, B. \& Goyette, E. (2004). Second language text comprehension: Processing within a multilayered system. The Canadian Modern Language Review, 61(1), 53-76. 
[34] Ehrlich, M. F. (1990). The processing of cohesion devices in text comprehension. Psychological Research, 53, $169-174$.

[35] Ellis, N. C. (2001). Memory for language. In P. Robinson (Ed.), Cognition and second language instruction (pp. 33-68). Cambridge: Cambridge University press.

[36] Erten, I., H., \& \& Raz1, S. (2009). The effects of cultural familiarity on reading comprehension. Reading in a Foreign Language, 21(1), 60-77.

[37] Fincher-Kiefer, R. (1992). The role of prior knowledge in inferential processing. Journal of Research in Reading, $15(1), 12-27$.

[38] Fincher-Kiefer, R., Post, T.A., Greene, T.R., \& Voss, J.F. (1988). On the role of prior knowledge and task demands in the processing of text. Journal of Memory and Language, 27, 416-428.

[39] Fukkink, R. G., Hulstijn, J., \& Simis, A. (2005). Does training in second-language word recognition skills affect reading comprehension? An experimental study. The Modern Language Journal, 89 (1), 54-75.

[40] Gernsbacher, M. A. \& Hargreaves, D. (1988). Accessing sentence participants: The advantage of first mention. Journal of Memory and Language, 26, 69-83.

[41] Grabe, W. (1991). Current developments in second language reading research. TESOL Quarterly, 25, 375-406.

[42] Grabe, W., \& Stoller, F. L. (2002). Teaching and researching reading. London: Longman.

[43] Hyde, J., \& Linn, M. (1988). Gender differences in verbal ability: a meta-analysis. Psychological Bulletin, 104 (1), $53-69$.

[44] Johnson, P. (1981). Effects on reading comprehension of language complexity and cultural background of a text. TESOL Quarterly, 15, 169-181.

[45] Kaylani, C. (1996). The influences of gender and motivation on EFL learning strategy use in Jordan. In R. Oxford (Ed.), Language learning strategies around the world: crosscultural perspectives (pp. 75-88). Honolulu: University of Hawaii, Second Language Teaching and Curriculum Center.

[46] Keshavarz, M. H., Atai, M. R., \& Ahmadi, H. (2007). Content schemata, linguistic simplification, and EFL readers' comprehension and recall. Reading in a Foreign Language, 19 (1), 19-33.

[47] Kintsch, W. (1994) Text comprehension, memory, and learning. American Psychologist, 49, $294-303$.

[48] Kintsch, W. (1998). Comprehension: A paradigm for cognition. Cambridge, England: Cambridge University Press.

[49] Koda, K. (2005). Insights into second language reading: a cross-linguistic approach. Cambridge: Cambridge University Press.

[50] Koda, K. (2007). Reading and language learning: Crosslinguistic constraints on second language reading development. Language Learning, 57(Suppl. 1), 1-44.

[51] Kozminsky, E., \& Kozminsky, L. (2001). How do general knowledge and reading strategies ability relate to reading comprehension of high school students at different educational levels? Journal of Research in Reading, 24 (2), $187-204$.

[52] Kuno, S. (1976). Subject, theme, and the speaker's empathy - A reexamination of relativization phenomena. In C. Li (Ed.), Subject and Topic (pp. 419-444). New York: Academic press.

[53] Linn, M. C., De Benedictis, T., Delucchi, K., Harris, A., \& Stage, E. (1987). Gender differences in national assessment of educational progress science items: what does “don't know" really mean? Journal of Research in Science Teaching, 24(3), 267-78.

[54] Mazzeo, J., Schmitt, A. P., \& Bleistein, C. A. (1993). Sex-related performance differences on constructed-response and multiple-choice sections of Advanced Placement Examinations. College Board Report, No. 92-7; ETS Research Report No. 93-5. New York: College Entrance Examination Board.

[55] McKenna, M.C., Kear, D.J., \& Ellsworth, R. A. (1995). Children's attitudes toward reading: A national survey. Reading Research Quarterly, 30(4), 934-956.

[56] McNamara, D. S. (2001). Reading both high-coherence and low-coherence texts: Effects of text sequence and prior knowledge. Canadian Journal of Experimental Psychology, 55, 51-62.

[57] McNamara, D.S., \& Kintsch, W. (1996). Learning from texts: Effects of prior knowledge and text coherence. Discourse Processes, 23, 247-288.

[58] Myers, D. G. (2002). Social psychology (7th ed.). New York: McGraw-Hill.

[59] Nassaji, H. (2002). Schema theory and knowledge-based processes in second language reading comprehension: A need for alternative perspectives. Language Learning, 52, 439-481.

[60] Oxford, R. L., Felkins, R. Z., Hollaway, G., \& Saleh, A. (1996). Telling their stories: language learners use diaries and recollective studies. In R. Oxford (Ed.), Language learning strategies around the world: cross-cultural perspectives (pp. 19-34) Honolulu:University of Hawaii, Second Language Teaching and Curriculum Center.

[61] Oxford, R. L., Park-Oh, Y., Ito, I., Sumrall, M. (1993). Learning a language by satellite: What influences achievement. System, $21,31-48$

[62] Pae, T. (2004). Gender effect on reading comprehension with Korean EFL learners. System, 32(3), $265-281$.

[63] Palincsar, A. S., \& Brown, A. L. (1984). Reciprocal teaching of comprehension-fostering and monitoring activities. Cognition \& Instruction, 1, 117-175.

[64] Pearson, P. D., \& Fielding, L. (1991). Comprehension instruction. In R. Barr, M. L. Kamil, P. Mosenthal, \& P. D. Pearson (Eds.), Handbook of reading research (pp. 815-860). White Plains, NY: Longman.

[65] Perfetti, C. A., Landi, N., \& Oakhill, J. (2005). The acquisition of reading comprehension skill. In Margaret Snowling and Charles Hulme (eds.), The Science of Reading: A Handbook, (227-247). Malden: Blackwell.

[66] Pressley, M. (2000). What should comprehension instruction be the instruction of? In M. L., Kamil, P. B., Mosenthal, \& P. D., Pearson (Eds.), Handbook of reading research (pp. 545-561). Mahwah, NJ: Erlbaum.

[67] Pressley, M., Wharton-McDonald, R., Mistretta-Hampton, J. M., \& Echevarria, M. (1998). The nature of literacy instruction in ten grade 4/5 classrooms in upstate New York. Scientific Studies of Reading, 2, 159-194.

[68] Prestin, E. (2008). Writing and reading. In G. Rickheit and H. Strohner (Eds), Handbook of Communication Competence (pp. 225-256). Mouton de Gruyter: Walter de Gruyter GmbH \& Co. KG, Berlin.

[69] Pulido, D. (2004). The effects of cultural familiarity on incidental vocabulary acquisition through reading. The Reading Matrix, 4(2), 20-53.

[70] Rosén, M. (2001). Gender differences in reading performance on documents across countries. Reading and Writing: An 
Interdisciplinary Journal, 14(1), 1-38.

[71] Rumelhart, D.E. (1980). Schemata: the building blocks of cognition. In R.J., Spiro, B.C., Bruce \& W.F. Brewer (eds.) Theoretical Issues in Reading Comprehension (pp. 33-58). Hillsdale, NJ: Erlbaum.

[72] Salmero'n, L., Kintsch, W., \& Cañas, J. J. (2006). Reading strategies and prior knowledge in learning from hypertext. Memory and Cognition, 34, 1157-1171.

[73] Sarig, G. (1987). High level reading in the first and the foreign language: Some comparative process data. In J. Devine, P. Carrell \& D. Eskey (Eds.), Research in reading English as a second language (pp. 105-120). Washington: TESOL.

[74] Sheldon, A. (1974), The role of parallel function in the acquisition of relative clauses in English. Journal of Verbal Learning and Verbal Behavior, 13, 272-81.

[75] Sheorey, R. (1999). An examination of language learning strategy use in the setting of an indigenized variety of English. System, $27,173-190$.

[76] Singhal, M. (2001). Reading proficiency, reading strategies, metacognitive awareness and FL readers. The Reading Matrix, 1(1), $1-10$.

[77] Smith, M.W., \& Wilhelm, J. D. (2002). Reading don't fix no Chevy's: literacy in the lives of young men. Portsmouth, NH: Heinemann.

[78] Stevenson, R. J., Crawley, R. A., \& Kleinman, D. (1994). Thematic Roles, Focus and the Representation of Events. Language and Cognitive Processes, 9(4), 473-592.

[79] Swaffar, J., Arens, K., \& Byrnes, H. (1991). Reading for meaning: An integrated approach to language learning. Englewood Cliffs, NJ: Prentice Hall.

[80] Van den Broek, P., Rapp, D. N., \& Kendeou, P. (2005). Integrating memory-based and constructionist processes in accounts of reading comprehension. Discourse Processes, 39, 299-316.

[81] Van Oostendorp, H. (1991). Inferences and integrations made by readers of script-based texts, Journal of Research in Reading, $14(1), 3-20$.

[82] Voss, J. F., Vesonder, G.T., \& Spilich, G. J. (1980). Text generation and recall by high knowledge and low-knowledge individuals. Journal of Verbal Learning and Verbal Behavior, 19, 651-667.

[83] Wei (2009). Gender differences in reading comprehension for Chinese secondary school students. A Seminar Paper Presented to the Graduate Faculty; University of Wisconsin-Platteville.

[84] Werner, P. K., \& Nelson, J. P. (2007). Mosaic 2: grammar. New York: McGraw-hill.

[85] Yongqi, G (2002). Gender, academic major, and vocabulary learning strategies of Chinese EFL learners. RELC Journal, 33(1), 35-54.

Alireza Ahmadi received his Ph.D. in TEFL from the University of Isfahan in 2008, his MA in TEFL from Shiraz University in 2002 and his BA in English Translation from the University of Allameh Tabatabaei in 2000.

Currently, he is an assistant professor in the Department of Foreign Languages and Linguistics at Shiraz University, Iran. His main interests include Language Assessment and Second Language Acquisition.

Shaban Mansoordehghan received his MA in TEFL and his BA in English Language and Literature both from the University of Allameh Tabatabaei, Tehran, Iran in 2003 and 2001 respectively.

Currently, he is a Lecturer at the Islamic Azad University of Hashtgerd, Iran. His main interests are Language Assessment and Second Language Acquisition. 